\title{
Left Far Lateral Craniotomy for Clipping of a Posterior Inferior Cerebellar Artery Aneurysm
}

\author{
Xiaochun Zhao ${ }^{1}$ Robert T. Wicks ${ }^{1} \quad$ Celene B. Mulholland ${ }^{1}$ Andrew F. Ducruet ${ }^{1}$ Peter Nakaji ${ }^{1}$ \\ 1 Department of Neurosurgery, Barrow Neurological Institute, \\ St. Joseph's Hospital and Medical Center, Phoenix, Arizona, \\ United States

\begin{abstract}
Address for correspondence Peter Nakaji, MD, Department of Neurosurgery, Barrow Neurological Institute, St. Joseph's Hospital and Medical Center, 350 West, Thomas Road; Phoenix, AZ 85013,
\end{abstract} \\ United States (e-mail: Neuropub@barrowneuro.org).
}

J Neurol Surg B 2019;80(suppl S4):S341-S342.

\begin{abstract}
Keywords

- aneurysm

- craniovertebral junction

- far lateral approach

- posterior inferior cerebellar artery

Objectives The complex anatomical relationships of neurovascular structures at the craniovertebral junction make the clipping of a posterior inferior cerebellar artery (PICA) aneurysm surgically challenging. We demonstrate the clipping of a PICA aneurysm in the video.

Design, Setting, and Participant A 65-year-old woman presented with a nonsymptomatic unruptured left PICA aneurysm; follow-up angiography showed an increase in its size. Preoperative angiography demonstrated a PICA aneurysm with the neck close to the origin of the PICA. A daughter sac of the aneurysm was also noted. A left far lateral approach was performed. The vagoaccessory triangle was exposed after opening the arachnoid membrane. The origin of the PICA and the aneurysm were revealed after exploration. The aneurysm neck was identified both proximally and distally. Two fenestrated clips were applied; subsequent indocyanine green (ICG) videoangiography demonstrated that the PICA was obstructed. One clip was adjusted, and repeated ICG videoangiography showed the PICA was patent. An endoscope was used before and after the clip application to better understand the anatomy of the aneurysm and inspect clip positions (- Fig. 1).

Outcome The patient was neurologically intact postoperatively and was discharged on postoperative day 4 .

Conclusion PICA aneurysms require careful treatment. Impingement of adjacent structures can cause severe complications. Lower cranial nerve damage can cause dysphagia, and compromised vertebral/PICA circulation can cause brainstem symptoms, such as Wallenberg's syndrome. Intraoperative ICG videoangiography should be used to evaluate vessel patency, and the endoscope should be used to fully inspect the aneurysm and evaluate the clip application.

The link to the video can be found at: https://youtu.be/dKxFQTRA89g.
\end{abstract}

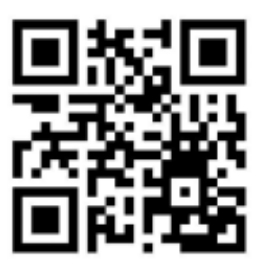

received

April 1, 2019

accepted

August 25, 2019

published online

October 22, 2019 www.thieme.com/skullbasevideos

www.thieme.com/jnlsbvideos (c) 2019 Georg Thieme Verlag KG Stuttgart · New York

License terms

10.1055/s-0039-1698825. ISSN 2193-6331. 


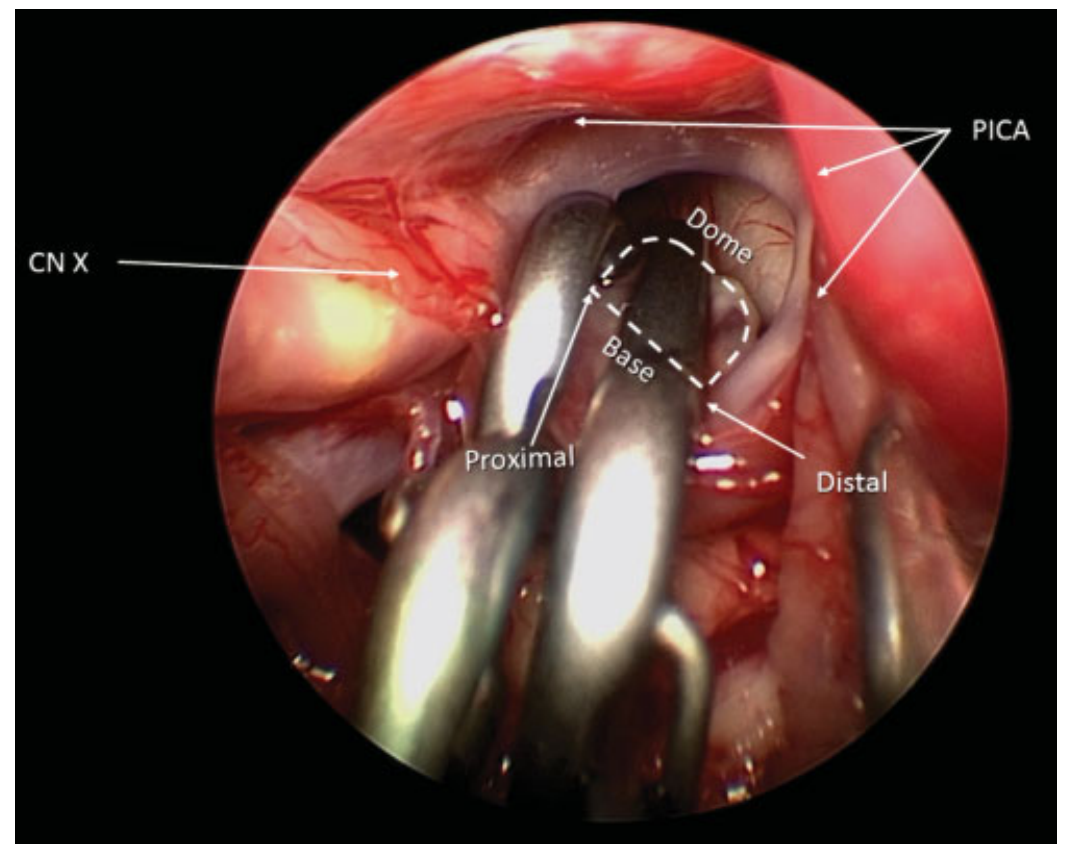

Fig. 1 An endoscopic view after the final clipping of the aneurysm. The PICA curves from the medial to the lateral side. The neck of the aneurysm is fully closed. CN, cranial nerve; PICA, posterior inferior cerebellar artery. (Used with permission from Barrow Neurological Institute, Phoenix, Arizona).

\section{Disclosures}

None.

Financial Support

None.

\section{Conflict of Interest}

None declared.

\section{Acknowledgments}

The authors thank the staff of Neuroscience Publications at Barrow Neurological Institute for assistance with manuscript and video preparation. 